Sonnenburg et al.

Figure S5

A.

\title{
B. thetaiotaomicron
}

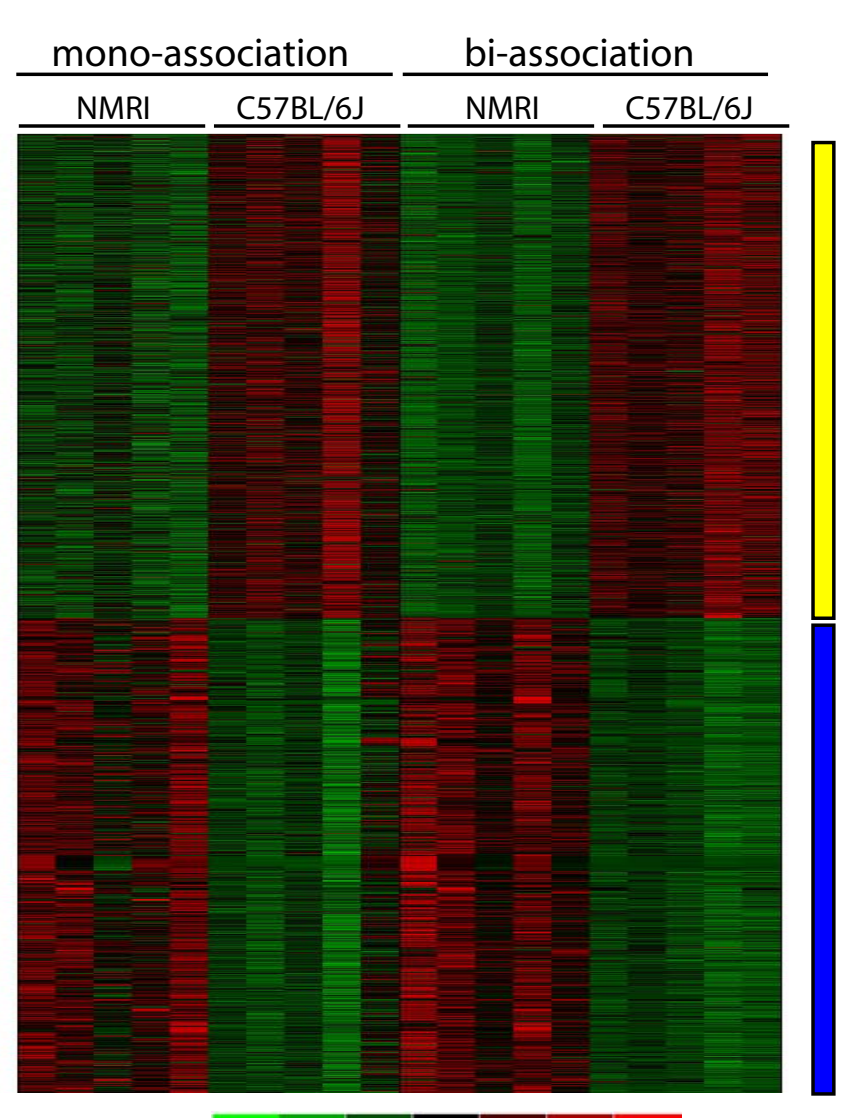

1201 genes

1168 genes

$\begin{array}{lllllll}-3.0 & -2.0 & -1.0 & 0 & 1.0 & 2.0 & 3.0\end{array}$

B.

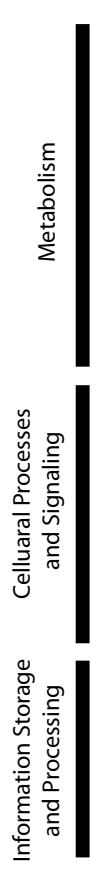

Secondary metabolites biosynthesis, transport and catabolism

Inorganic ion transport and metabolism Inorganic ion transport and metabolism

Coenzyme transport and metabolism Nucleotide transport and metabolism Amino acid transport and metabolism Carbohydrate transport and metabolis Energy production and conversio Posttranslational modification, protein turnover, chaperone Intracellular trafficking, secretion, and vesicular transpo Cell w all/membrane/envelope biogenes is Signal transduction mechanism Signal transduction mechanism

Cell cycle control, cell division, chromosome partitionin Replication, recombination and repair Transcription

Translation, ribosomal structure and biogenesis
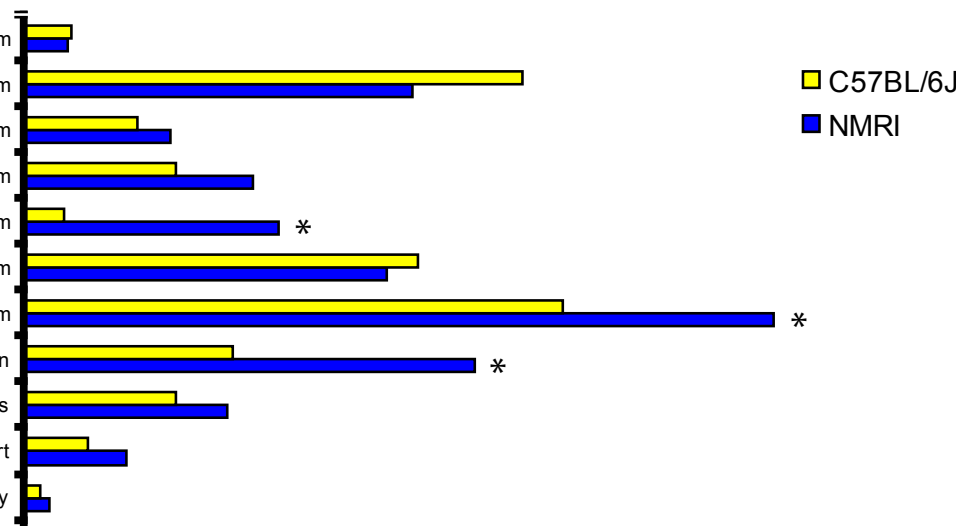

- 